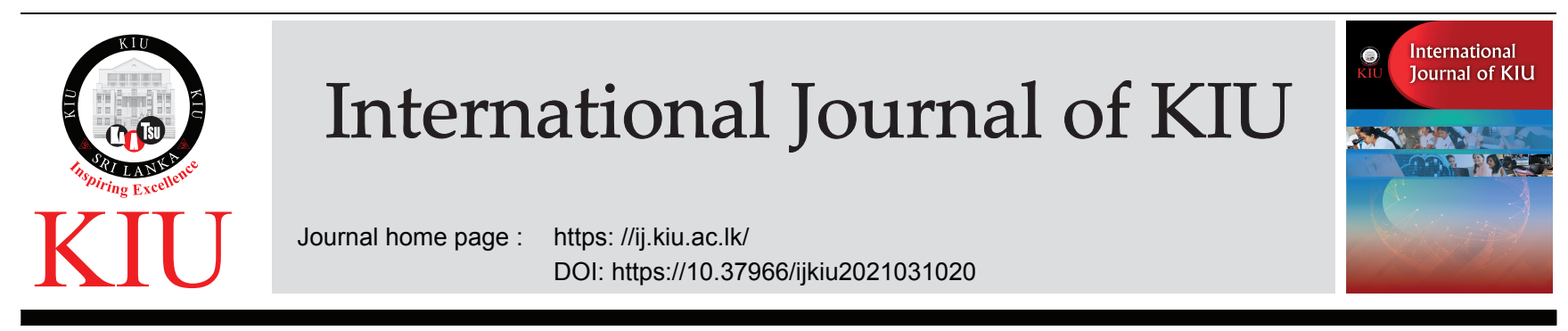

Review Article

\title{
Host Genetic Susceptibility and Impacts of Dietary Factors on Covid-19
}

\author{
Ranadeva, N. D. K. ${ }^{*}$, Gunathilaka M. D. T. L. ${ }^{2}$ \\ ${ }^{1}$ Department of Biomedical Science, Faculty of Health Sciences, KIU, Battaramulla, Sri Lanka. \\ ${ }^{2}$ Department of Acupuncture, Facuty of Health Sciences, KIU, Battaramulla, Sri Lanka.
}

Article history:

Received $20^{\text {th }}$ October 2021

Received in revised form

$28^{\text {th }}$ December 2021

Accepted 30 ${ }^{\text {th }}$ December 2021

Cite as:

Ranadeva, N.D.K, Gunathilaka M.D.T.L (2021) Host Genetic Susceptibility and Impacts of Dietary Factors on Covid-19 International Journal of KIU, 3(1), 13-24 doi:https://10.37966/ijkiu2021031020 \#Corresponding author: nadeeka@kiu.ac.lk

\begin{abstract}
COVID-19, a disease caused by SARS coronavirus 2 (SARS-CoV-2) has been a virus which is causing a global issue due to the fact that it resulted in a pandemic. The SARS coronavirus 2 binds with the angiotensin-converting enzyme 2 (ACE-2) receptors expressed in various human organs including the lungs. The SARC-CoV-2 causes respiratory disease ranging from mild to life-threatening pneumonia. Covid-19 is much feared due to its ultimate outcome such as multi-organ damage as a result of the production of a high level of pro-inflammatory cytokines referred to as "cytokine storm and resulting increased mortality and morbidity. Outcomes of the COVID 19 infection are associated with several factors that include demographic, environmental, behavioural, dietary, and genetic factors. In addition, male gender, ethnicity, older age, obesity, and several chronic diseases affect the severity of the disease. Genetic susceptibility and dietary factors involved with COVID - 19 infectivity are current areas that are widely researched and likely to play a major role. Through Genome Wide Association Studies (GWAS) and other studies done worldwide, scientists have discovered variants related to the susceptibility and severity of COVID-19. Among published reports, the involvement of ACE-2, TMPRSS2, 3p21.31 gene cluster, OAS1, OAS2 and OAS3, TYK2, DPP9, IFNAR2, CCR2 TMEM189-UBE2V1 genes, IFNL4, TLR7, LZTFL1, CCHCR1, CCNG1, ACSF3, FPR1, NKG2C/HLA-E, NLRP3, DNAH7 and CLUAP1, DES and SPEG, STXBP5, TOMM7, WSB1, PIEZO1, SCN5A, APOL1, PRKRA, GC, NADSYN1, VDR, and CYP2R1, PPCDC, VDR, DMGDH is summarized in this review. Similarly, this review concluded the role of nutrition in terms of the importance of a balanced diet and functional foods, micronutrients, probiotics, and how the omega 3/omega 6 ratio helps to prevent the severity of COVID-19.
\end{abstract}

Key words: COVID 19, Genetic susceptibility, Nutrition, SARS-CoV-2 


\section{Introduction}

Since the onset of the covid pandemic, scientists have been investigating the reasons behind the variability of Covid 19 symptoms. Some individuals manifest severe life-threatening symptoms while others only have mild or negligible symptoms. Studies across the globe currently is in an attempt to shed light on the susceptibility factors of the host associated with the severity (Asgari and Pousaz, 2021).

The COVID-19 symptoms can be described in a spectrum, categorized in to asymptomatic, mild to moderate, severe, and critical disease. Fever, cough, headache, fatigue, and breathing difficulties are among the most common symptoms. It has been reported that nearly a one third of the individuals are asymptomatic. Among the symptomatic population, nearly $80 \%$ has been reported as having mild or moderate symptoms while the remainder manifests severe symptoms including severe breathing difficulty, and lung damage where approximately $5 \%$ out of the latter develops respiratory failure, ARDS, shock or multiple organ failure leading to death (Velavan et al., 2021).

The association of demographic factors, environmental factors, behavioural factors, other diseases, dietary patterns, and genetic factors with Covid - 19 symptoms have been described by several studies previously. Advanced age, male sex, obesity and other non-communicable diseases have been identified to be related to increased severity of the disease (Grivas et al., 2021). Ethnicity also has been identified as a probable factor associated with the severity of Covid- 19, which has paved the path to investigate genetic variants across the human genome in Covid - 19 patients in different ethnicities and different groups of people (Hu et al., 2021). Diet plays a huge role in human life where health and diet have been described under many contexts. Researchers have also investigated the effect of dietary patterns on the severity of Covid - 19 (Salazar-Robles et al., 2021).
Therefore, this review, summarizes the association of genetic factors and dietary factors with the increased susceptibility and severity of Covid-19.

\section{Host Genetic susceptibility for Covid - 19}

Worldwide scientists are interested in the phenomenon of individual inter variability when it comes to the severity of infectious diseases, where attention is invariably has been towards investigating the genetic factors through Genome Wide Association Studies (GWAS). It has been challenging to identify the impact of genetic variants on infectious diseases due to the other major influential factors such as health care access and socio-demographic factors. Scientists all over the world have collaborated to form large definitive study populations related to Covid-19 to investigate the genetic impact and the severity of Covid-19 symptoms (Asgari and Pousaz, 2021).

Similarly, another GWAS study conducted with 1980 Covid-19 patients, has confirmed the presence of the $3 \mathrm{p} 21.31$ gene cluster comprising signals from 6 genes (i.e: SLC6A20, LZTFL1, CCR9, FYCO1, CXCR6, and XCR1) as a locus for genetic susceptibility in patients infected by Covid-19 who were suffering from respiratory failure. This locus also showed a probable connection to the $\mathrm{ABO}$ blood grouping system with the detection of an association signal at locus 9q34.2 (rs657152) responsible for ABO grouping system (Severe Covid-19 GWAS Group et al., 2020). The study has detected the variant rs11385942 (insertion-deletion GA or G variant) as a potential risk variant. The GA allele is associated with the reduced expression of CXCR6 and increased expression of SLC6A20, and LZTFL1 which are connected to lung cells (Severe Covid-19 GWAS Group et al., 2020). The GA allele of the variant rs11385942 further has been confirmed as a risk allele as it has been identified in higher frequency from patients under mechanical ventilation compared to those who only require oxygen supplementation (Severe Covid-19 GWAS Group et al., 2020). The study further has identified the blood group " $A$ " having a higher risk than other blood groups and a 
probable protection expressed in blood group "O" compared to other blood groups through the association signals between rs11385942 and rs657152 (Severe Covid-19 GWAS Group et al, 2020). An interesting discovery following the findings of Severe Covid-19 GWAS Group et al, 2020 was that the region of risk loci is inherited from Neanderthals and is seen in almost half the South Asian populations and around 16\% in Europe (Zeberg and Pääbo, 2020).

Another genome wide study including 2,244 severely ill COVID-19 patients has reported novel significant associations on chromosome 12q24.13 (rs 10735079) in a gene cluster (OAS1, OAS2 and OAS3) encoding activators of antiviral restriction enzyme; on chromosome 19p13.2 (rs74956615) related to the gene encoding tyrosine kinase 2 (TYK2); on chromosome 19p13.3 (rs2109069) encoding dipeptidyl peptidase 9 (DPP9); and on chromosome 21q22.1 (rs2236757) related to interferon receptor gene IFNAR2. This study has also revealed that the monocyte-macrophage chemotactic receptor CCR2 is also associated with severe COVID-19 (Pairo-Castineira et al., 2020).

IL-1 is found to be elevated in COVID-19 patients especially critical patients with severe symptoms who suffer from the cytokine storm (Wang et al., 2020). GWAS conducted among 332 COVID-19 patients in Hong Kong has identified a significant gene variant (rs6020298) located in IL-1 signalling pathway that enhances the level of IL-1 which aggravates the severity of COVID-19 in a read-through transcript TMEM189-UBE2V1 in the $20 \mathrm{q} 13.13$ region that is found to be connected with the innate immune signalling. Further the blockage of IL-1 in critical patients of COVID-19 in one of the clinical studies have shown that the respiratory function to be improved in $72 \%$ of the patients (Wang et al., 2020).

LZTFL1 gene variant rs73064425 has a possible action in impairment of respiratory epithelial cell function (Rescenko et al., 2021) where this has been identified in increased frequency from critical COVID-19 patients (Horowitz et al., 2020) and may indicate a probable impact on increasing the severity of COVID-19 symptoms. CCHCR1 produces a protein that is involved in cytoskeletal remodelling and mRNA turnover, where the variant rs143334143 of CCHCR1 gene has been identified to impair this function. Further this variant (rs143334143) has been identified in high frequency in critically ill patients of COVID-19 (Horowitz et al, 2020). Variants of DPP9 that enhances the dipeptidyl peptidase secretion may have a possible influence on COVID-19 severity, where increased expression of the variant rs2277732 of DPP9 in severe covid-19 patients was detected (Horowitz et al., 2020). Further 3 novel variants; CCNG1 (rs79833209), ACSF3 (rs4782327), FPR1 (rs12461764) were discovered as common genetic variants that affect the COVID-19 susceptibility and severity by another GWAS (Horowitz et al., 2020). The mechanisms by which these affect the severity has not been clearly explained, thus further investigations must be carried out in this avenue.

According to the UK biobank data, 8 potential genetic risk loci associated with mortality of COVID-19 has been identified. The 8 super variants have been identified in a consistent manner across populations with respect to Covid-19 related deaths. Genes DNAH7 and CLUAP1 (cilia dysfunction), DES and SPEG (cardiovascular disease), STXBP5 (thromboembolic disease), TOMM7 (mitochondrial dysfunctions), WSB1 (innate immune system), and DNAH7 (newly identified gene in bronchial epithelial cells, downregulated in SARS-CoV-2 patients) (Hu et al., 2021). Another study conducted using UK biobank data has discovered a connection between the gene PIEZO1 and COVID-19 mortality. PIEZO1 is a gene that moderates the epithelial cell response to blood flow by encoding proteins which make a cation channel as well as may have a role in pulmonary inflammation (Cheng et al., 2020). The exact mechanism by which this gene is associated to COVID-19 severity is still under investigation. The same study also has stated the susceptibility of ethnic groups with respect to the variants of the gene PIEZO1 (Cheng et al., 2020). 
Interferons play a vital role in host antiviral signalling and stimulate release of crucial components of the early host response to viral infection. Interferons (IFNs) are considered a crucial molecule for the COVID-19 disease outcomes as well. A case (177 patients) and control (445 healthy individuals) study revealed that IFNL4 gene variants (affects production of interferons) may be predisposing to the outcomes of COVID-19 (Saponi-Cortes et al., 2021). IFNAR2- rs13050728 which is a loss of function mutation in the type-1 interferon receptor also increases the severity of the disease (Horowitz et al, 2020). Elevated expression of the interferon receptor subunit IFNAR2 with respect to the studies conducted in order to discover the beneficial role for type I interferons has shown reduced risk for severe form of COVID-19 (Pairo-Castineira et al., 2021). Another study has also identified the probable connection of IFNAR2 gene to COVID - 19 susceptibilities as well as prognosis (Liu et al., 2020). A whole genome sequencing study using 4 cases of young men severely affected by Covid-19 (two unrelated families) discovered a noteworthy loss-of-function variants in TLR7 gene that stimulate IFN- $\gamma$ which is located in $\mathrm{X}$ chromosome (Van der Made et al., 2020).

A study finding has concluded that variants in NKG2C/HLA-E axis (KLRC2del and HLA-E*0101) to have an impact on severity of SARS-CoV-2 infection, thereby thought to be useful as a potential predictor of high-risk for severe COVID-19 (Vietzen et al., 2021).

NLRP3 gene has been identified as a main player of the innate immune system which mediates the organization of host-immune response. Single nucleotide variants in the NLPR3 gene (rs10754558 $\mathrm{C}>\mathrm{G}$ and $\mathrm{rs} 10157379 \mathrm{~T}>\mathrm{C}$ ) were found to be positively associated with SARS-CoV-2 infectious symptoms, in a study conducted using 308 critically ill COVID-19 patients. The study also concluded that rs10754558 $\mathrm{C}>\mathrm{G}$ of the NLPR3 gene to be a significant predictor of the risk of COVID - 19 susceptibility and severity (Maes et al., 2021).
The genetic susceptibility for COVID-19 associated cardiac involvement has been described by a group of researchers where a variant of SCN5A gene (p. Ser1103-Tyr) has been identified in a cohort of diseases affected African males (Giudicessi et al., 2021). APOL1 gene has also gained attention with respect to Kidney involvement of COVID-19 disease in individuals with African ancestry (Friedman, 2021).

ACE-2 (Angiotensin-2 Conversion Enzyme) has been found as a mediating protein for SARS-CoV-2 to access the human host cells. SARS-CoV-2 gains entry to host type II lung cells by binding ACE2. SARS-CoV-2 binding to ACE2 is facilitated by transmembrane protease, serine 2 (TMPRSS2), which cleaves one of the surface proteins of the virus. Therefore, variations that will result in upregulation of both these ACE 2 and TMPRSS2 in host cells increase the SARS-CoV-2 infectivity. Both these enzymes are regulated by Androgen Receptor gene explaining the increased susceptibility of male gender to the severe form of the disease (McCoy et al., 2020) (Strope et al., 2020) (Gibson et al., 2020). Scientists also have predicted that the gene variants that are associated with diseases such as androgenetic alopecia, prostate cancer, benign prostatic hyperplasia, and polycystic ovary syndrome can also be associated with increased risk of COVID-19 susceptibility. However, further studies are necessary for the establishment of these connections (Wambier et al., 2020) (McCoy et al., 2020). Further ongoing studies investigate the length of CAG repeats in the Androgen Receptor gene in COVID-19 patients (McCoy et al., 2020). An Italian group of researchers also have discovered the relation of TMPRSS2 gene variant as a potential predictor of risk in male patients (Asselta et al., 2020). Singh et al., (2021) also describes the association of ACE2 and TMPRSS2 variants withthe severity or protection from COVID-19 in different populations (Singh et al., 2021).

Another study has discovered the variants in TMPRSS2 gene (c.331G $>A$, c. $23 \mathrm{G}>\mathrm{T}$, and c. $589 \mathrm{G}>\mathrm{A}$ ) connected to the viral entry to human cells (Latini et al., 2020). Apart from ACE-2 and 
TMPRSS2 there are other proteins that are involved with the entry of this virus. A study conducted using 131 Covid-19 patients have discovered a missense variant in PCSK3 gene (c.893G $>$ A) (Latini et al., 2020) connected with the severity. A cohort study (35 COVID -19 patients) showed that variants in a protein kinase enzyme (activated by viral RNA); protein kinase activator A, also known as PRKRA, to be having an impact on the immune response mediated by IFN (Benetti et al., 2020)

Proper nutrition with vitamins and minerals is essential for an efficient immune system. Vitamin D, Zinc and Selenium are some of the nutrients that are responsible for a healthy immune system and have been discovered to be important in prevention and recovery from COVID-19 infection. Vitamin D has further been identified as an important nutrient neutralizing the SARS-CoV-2 impact through the viral binding to the VDR receptor supporting in the control of immune response. A study conducted using a population of COVID- 19 infected patients in UAE has discovered 12 genetic variants in Vitamin D related genes GC, NADSYN1, VDR, and CYP2R1 (Al-Anouti et al., 2021). Variants related to vitamin D status, Zinc and Selenium levels have been found in increased frequency in a study conducted using 120 Serbian individuals (Adult and paediatric) infected with Covid- 19 (DHCR7/NADSYN1 rs12785878, GC rs2282679, CYP2R1 rs10741657, and VDR rs2228570 variants related to Vitamin D; PPCDC rs2120019 variant related to Zinc and DMGDH rs 17823744 related to selenium) (Kotur et al., 2021).

Genomic studies to understand the influential factors of the host for COVID - 19 is a rapidly expanding research field as well as it can be of high importance in the aspects of understanding the multiorgan involvement, virulent factors of the virus, risk prediction, prevention, treatment, and management of COVID - 19. This knowledge can be used for downstream processes such as developing drugs or vaccines for the current and novel variants of the SARS-CoV-2.

\section{Role of nutrition in Covid 19 susceptibility and severity.}

Nutrition/diet is one of the important environmental factors that interact with our genetic makeup to maintain normal development and homeostasis. A balanced diet provides all essential nutrients required to the body and it helps to maintain a healthy body status by reducing the risk of chronic non-communicable diseases including type 2 diabetes mellitus, cardiovascular diseases, and cancer (Simopoulos et al., 2021). A poor diet is considered as one of the leading factors for death and according to the statistics where one in five global deaths are associated with poor diet (Afshin et al., 2019).

Most people infected with SARS-CoV-2 showed no symptoms or mild symptoms which can further progress into a life-threatening condition due to several factors. People who are suffering from severe pulmonary diseases, chronic non-communicable diseases, and immunocompromised patients are more vulnerable to Covid-19 infection. In addition, obesity is considered as one of the main risk factors that cause the severity of the disease (Skrajnowska et al., 2021). People with an increased BMI have a poor prognosis of the disease due to the high pressure in the pleural cavity and reduced lung recruitment capacity which in turn causes atelectasis and alveolar collapse (Hibbert, Rice and Malhotra, 2012). Other than that, adipose tissue in obese people produces a high level of pro-inflammatory cytokines which in turn exacerbate the inflammatory conditions in people with COVID-19 and lead to acute respiratory distress syndrome or multiple organ failure (Makki Froguel and Wolowczuk, 2013). Similarly, cardiovascular diseases and diabetes have been discovered as two other coinciding diseases with COVID-19. People with diabetes have a high potential of getting the severe form of COVID-19 due to the excessive secretion of cytokines, interleukin-6, and C-reactive protein which exacerbates the inflammatory states (Tsalamandris et al., 2019). Therefore, it is necessary to find a way to reduce the cytokines storm in high-risk 
groups of COVID-19. Diet plays an important role influencing the levels of gene expression of cytokines and thus modulate inflammation and oxidative stress associated with Covid 19 infection (Lange,2021). People who are infected with COVID 19 have dysregulated immune response by increased secretion of cytokines and attenuated interferon response to the pathogenic virus. This status is further enhanced by conditions of obesity and diabetes mellitus by decreasing the interferon response without infections (Santos et al., 2021).

Although there are several factors associated with the pathology of Covid-19, insulin resistance is considered as one of the main risk factors that cause impairment of metabolic functions (Govender et al., 2021). Therefore, people who are suffering from the disorders of insulin resistance such as diabetes and obesity should consume a low carbohydrate diet as it provides a safe and effective way to maintain glycaemic control and evade insulin resistance (Skrajnowska et al., 2021).

In addition, nutritional status plays a key role as a driver of SARS-CoV-2 virulence. It has been identified that malnutrition has a direct impact on Covid 19 progression as it is the primary cause of immunodeficiency worldwide (James et al., 2021). An inadequate diet and the resulting malnutrition impair the immune response in Covid 19 patients which in turn increase the mortality rate due to poor fighting capacity against the disease (Mertens and Penalvo, 2021). In this context, some nutrients are already highlighted for their role in improving the immune response thereby lowering the susceptibility for COVID 19 infection (Octavia and Harlan, 2021).

Long-chain polyunsaturated fatty acids including omega-3 and omega- 6 are mainly involved with the regulation of inflammation (DiNicolantonio and O'Keefe, 2018). Hence, the deficiency can lead to an increase in the susceptibility to viral diseases including novel coronavirus. Omega-6 fatty acid acts as a substrate to produce pro-inflammatory prostaglandins and leukotrienes which help to enhance the immune response over invasion by pathogens (Innes and Calder, 2018). Whereas omega-3 fatty acids suppress the immune responses by inhibiting the activation of neutrophils and monocytes. As omega-6 and omega-3 fatty acids and their metabolites have opposing properties, a balanced ratio is important to maintain health. Therefore, a diet rich in omega 6 and low in omega 3 should be consumed to enhance the immune responses against inflammation. It is recommended to use a mixture of fish fatty acids including docosahexaenoic acid $($ DHA) + eicosapentaenoic acid (EPA) to reduce oxidative stress and the symptoms of acute respiratory distress in Covid 19 (Skrajnowska et al., 2021).

Micronutrients also play a major role in supporting the immune system. Vitamin B group plays a vital role in the amino acid synthesis, tissue formation, and the regulation of gene expression. Among the Vitamin B group, Vitamin B6 (pyridoxal 50-phosphate) regulates the immune function as a co-factor in generating metabolites with immunomodulating effects. Therefore, the deficiency will ultimately lead to the deterioration of protein synthesis and tissue formation (Shakoor et al., 2021). Similarly, Vitamin $\mathrm{C}$ helps to boost the immune system by synthesizing the antioxidant in the skin which in turn enhances the barrier function against pathogens. Further, Vitamin $\mathrm{C}$ is associated with the maintenance of immunity by accumulating in phagocytic cells to enhance chemotaxis, phagocytosis, generation of reactive oxygen species, and ultimately microbial killing (Carr and Maggini, 2017). Due to the antioxidant and free radical scavenging activities of Vitamin $C$, it has the ability to fight against COVID 19. Clinical trials have confirmed that the ability of Vitamin C to reduce the frequency, duration, and severity of the common cold and the incidence of pneumonia. Most importantly, it has proved that the high-dose of intravenous vitamin $\mathrm{C}$ may help to reduce cytokine storm in severe SARS-CoV-2 infection. Therefore, the consumption of Vitamin C-rich foods is important to maintain the daily requirement to reduce the predisposition to COVID 19 infection (De Melo and Homem-de-Mello,2020). 
Vitamin D also reduces the infection by modulating the formation of antimicrobial proteins including defensins, and cathelicidins in the skin. In addition, Vitamin D receptors present in immune cells are responsible for modulating the responses to viral lung diseases and protecting against infectious respiratory diseases in the prevention of COVID-19 (Octavia and Harlan, 2021). Further studies reported that vitamin D deficiency as a risk factor for COVID-19 infection (Jude et al., 2021). Further, Whittemore (2020) has identified that the rates of COVID 19 infection are higher in countries at higher latitudes due to the low exposure to sunlight. Hence, people should mainly focus on a diet rich in Vitamin D to reduce the infection of COVID 19. Among the different types of food, fatty fish and egg are considered as good sources of Vitamin D (Whittemore,2020).

Further, zinc and selenium play an important role in the regulation of immune response. Selenium can protect the immune system mainly from viral infections by increasing the production of interleukin-2 (IL-2) which exhibits immunomodulatory effects (Khatiwada and Subedi 2021). Therefore, selenium can improve the immunomodulatory effects in patients infected with SARS-Cov-2. Similarly, zinc can also regulate the inflammatory responses by activation, proliferation, and maturation of the immune cells such as leukocytes and lymphocytes. In addition, zinc can prevent the SARS-Cov-2 from entering cells. Hence, adequate levels of zinc and selenium are important for immune function and viral clearance of SARS-CoV-2 infection (Nikola et al., 2021).

Polyphenols, flavonoids, and carotenoids are bioactive compounds that exhibit antiviral properties. Polyphenols are naturally found in fruits and vegetables other than cereals, dry legumes, chocolate, and beverages, such as tea and coffee which exhibit potent antioxidant and anti-inflammatory effects. Polyphenols have been identified as the potential bioactive compound that can be used to prevent respiratory viral infections including COVID 19 (Paraiso, Revel and, Stevens, 2020). Polyphenols can block the angiotensin-converting enzyme 2 (ACE-2) receptors that have been identified as the functional SARS-CoV-2 receptors to prevent the entry of the virus and its replication in the host cells (Lange, 2021). Similarly, flavonoids also exhibit antiviral and immunomodulatory effects, thereby reducing the risk of infection with SARS-CoV-2 by inhibiting various inflammatory cytokines. Flavonoids can also bind with ACE-2 receptors and block the entry of the SARS-CoV-2 virus (Alzaabi et al., 2021). In addition, carotenoids are a group of natural pigments that can act against inflammation and oxidative damage. Therefore, diets rich in carotenoids can be utilized in the treatment of the acute phase of COVID-19 by targeting the inflammatory storm resulting from viral infections (Khalil et al., 2021). Therefore, it is recommended to consume at least five portions of fruit and vegetables every day to gain the advantages of the above-mentioned bioactive compounds in the prevention of the severe form of COVID-19 infection.

Even though, it is commonly known that SARS-CoV-2 mainly affects the respiratory system, it can cause gastrointestinal infections as well. Intestinal endothelium contains receptors for the SARS-CoV-2 virus and the number of ACE-2 receptors increases with age by providing a potential entry mechanism for the SARS-CoV-2 virus. The entry of the SARS-CoV-2 virus can lead to imbalance of commensal gut microbiota (intestinal dysbiosis) that cause gastrointestinal infections. Therefore, probiotics provide some beneficial effects on intestinal dysbiosis by increasing the commensal bacteria including Lactobacillus and Bifidobacterium in people with COVID-19 infection a (Kurian et al., 2021). In addition, natural functional compounds are identified as potential agents that exhibit antiviral and immunomodulatory effects. For example, vitamin $\mathrm{C}$ in fruits such as pomegranate and elderberry, allicin in garlic and onion, piperine in black pepper, gingerols in ginger, curcumin in turmeric, kaempferol, and methylglyoxal in honey are considered as health-promoting food ingredients to mitigate COVID-19 symptoms, however, the validated scientific evidence for the efficacy of these foods is not available 
(Skrajnowska et al., 2021).

The importance of a healthy diet in prevention and management of COVID-19 and its consequences have been discussed in various studies conducted across the world. Among them, many studies have confirmed the necessity of a well-balanced diet to enhance the immune response against Covid-19 viral infection. It has also been pointed out that a healthy diet rich in vitamins, minerals, and balanced ratio of omega 6 and omega 3 help to mitigate the severity of the condition. Therefore, it is important to consume nutrients according to the RDA (recommended dietary allowance) requirement to enhance the optimal function of the immune system and mitigate Covid-19 infection and outcomes.

\section{References}

Afshin, A., Sur, P.J., Fay, K.A. (2019). Health effects of dietary risks in 195 countries, 1990-2017: a systematic analysis for the Global Burden of Disease Study 2017: The Lancet, 393 (10184), 1958 - 1972.

Alzaabi, M. M., Hamdy, R., Ashmawy, N. S., Hamoda, A. M., Alkhayat, F., Khademi, N. N., Al Joud, S., El-Keblawy, A. A., \& Soliman, S. (2021). Flavonoids are promising safe therapy against COVID-19: Phytochem Re,1-22. DOI:10.1007/s11101-021-09759-z.

Asgari, S., Pousaz, L. A. (2021). Human genetic variants identified that affect COVID susceptibility and severity: Nature, 600(7889), 390-391. DOI: 10.1038/d41586-021-01773-7. PMID: 34239107.

Benetti, E., Giliberti, A., Emiliozzi, A., Valentino, F., Bergantini, L., Fallerini, C., Anedda, F., Amitrano, S., Conticini, E., Tita, R., d'Alessandro, M., Fava, F., Marcantonio, S., Baldassarri, M., Bruttini, M., Mazzei, M. A., Montagnani, F., Mandalà, M., Bargagli, E., Furini, S., Mari, F. (2021). Clinical and molecular characterization of COVID-19 hospitalized patients: PLoS One, 15(11). DOI:10.1371/journal.pone.0242534.

Carr, A. C., Maggini S. (2017). Vitamin C and Immune Function: Nutrients, 9(11), 1211. DOI:10.3390/nu9111211.
Cheng, C.W., Deivasikamani, V., Ludlow, M.J., Vecchis, D.D., Kalli, A. C., Beech, D.J.,Sukumar, P. (2021). Genetic variants of PIEZO1 associate with COVID-19 fatality: medRxiv, 5(6), 987.

Melo, A. F., Homem, D. M. (2020). High-dose intravenous vitamin $\mathrm{C}$ may help in cytokine storm in severe SARS-CoV-2 infection: Critical Care, 24 (500), 1-2. DOI: https://doi.org/10.1186/s13054-020-03228-3.

DiNicolantonio, J. J., O'Keefe, J. H. (2018). Importance of maintaining a low omega-6/omega-3 ratio for reducing inflammation: Open Heart, 5: e000946. DOI: 10.1136/openhrt-2018-000946.

Ellinghaus, D., Degenhardt, F., Bujanda, L., Fernández, J., Prati, D., Baselli, G., Asselta, R., Grimsrud, M. M., Milani, C., Aziz, F., Kassens, J., May, S., Wendorff, M., Wienbrandt, L., Uellendahl-Werth, F., Zheng, T., Karlsen, T. H. (2020). Genomewide Association Study of Severe Covid-19 with Respiratory Failure: The New England journal of medicine, 383(16), 1522-1534. DOI: https://doi.org/10.1056/ NEJMoa2020283.

Friedman, D. J. (2021). COVID-19 and APOL1: understanding disease mechanisms through clinical observation: Journal of the American Society of Nephrology, 32(1), 1-2. 
Gibson, W. T., Daniel, M.E., Jianghong, A., Jones, J.M. (2020). ACE 2 coding variants: a potential X-linked risk factor for COVID-19 disease: bioRxiv, 8(7), 768 .

Giudicessi, J. R., Dan, M. R., Arthur, A.M., Michael, J. A. (2020). "Genetic susceptibility for COVID-19-associated sudden cardiac death in African Americans: Heart rhythm, 17(9), 1487-1492.

Govender, N., Khaliq, O. P., Moodley, J., \& Naicker, T. (2021). Insulin resistance in COVID-19 and diabetes: Prim Care Diabetes,15(4), 629-634. DOI: 10.1016/j.pcd.2021.04.004.

Hibbert, K., Rice, M., Malhotra, A. (2012). Obesity and ARDS: Chest, 142(3), 785-790. DOI:10.1378/chest.12-0117.

Horowitz, J. E., Kosmicki, J. A., Damask, A., Sharma, D., Roberts, G., Justice, A. E., Banerjee, N., Coignet, M. V., Yadav, A., Leader, J. B., Marcketta, A., Park, D. S., Lanche, R., Maxwell, E., Knight, S. C., Bai, X., Guturu, H., Sun, D., Baltzell, A., Kury, F., Ferreira, M. A. (2021). Common genetic variants identify therapeutic targets for COVID-19 and individuals at high risk of severe disease: MedRxiv, 5(3), 256.

Hu, J., Li, C., Wang, S., Li, T. and Zhang, H. (2021). Genetic variants are identified to increase risk of COVID-19 related mortality from UK Biobank data: Human genomics, 15(1), 1-10.

Innes, J.K., Calder, P.C. (2018). Omega-6 fatty acids and inflammation: Prostaglandins Leukot Essent Fatty Acids ,132, 41-48. DOI: 10.1016/j.plefa.2018.03.004.

James, P. T., Ali, Z., Armitage, A. E., Bonell, A., Cerami, C., Drakesmith, H., Jobe, M., Jones, K. S., Liew, Z., Moore, S. E., Morales-Berstein, F., Nabwera, H. M., Nadjm, B., Pasricha, S. R., Scheelbeek, P., Silver, M. J., Teh, M. R., \& Prentice, A. M. (2021). The Role of Nutrition in COVID-19 Susceptibility and Severity of Disease: A Systematic Review: J Nutr, 151(7), 1854-1878. DOI:10.1093/jn/nxab059.

Jude, E. B., Ling, S. F., Allcock, R., Yeap, B., \& Pappachan, J. M. (2021). Vitamin D Deficiency Is Associated With Higher Hospitalization Risk From COVID-19: A Retrospective Case-control Study: The Journal of Clinical Endocrinology \& Metabolism, 106 (11), 4708-4715.DOI: https://doi.org/10.1210/ clinem/dgab439.

Khalil, A., Tazeddinova, D., Aljoumaa, K., Kazhmukhanbetkyzy, Z. A., Orazov, A., \& Toshev, A. D. (2021). Carotenoids: Therapeutic Strategy in the Battle against Viral Emerging Diseases, COVID-19: An Overview: Prev Nutr Food Sci, 26(3), 241-261. DOI:10.3746/pnf.2021.26.3.241.

Khatiwada, S., Subedi, A.A. (2021). Mechanistic Link Between Selenium and Coronavirus Disease 2019 (COVID-19): Curr Nutr Rep, 10(2), 125-136. DOI: 10.1007/s13668-02100354-4.

Kotur, N., Skakic, A., Klaassen, K., Gasic, V., Zukic, B., Skodric-Trifunovic, V., Stjepanovic, M., Zivkovic, Z., Ostojic, O., Stevanovic, G., Lavadinovic, L., Pavlovic, S., \& Stankovic, B. (2021). Association of Vitamin D, Zinc and Selenium Related Genetic Variants With COVID-19 Disease Severity: Front Nutr, 8, 43. doi:10.3389/fnut.2021.689419

Kurian, S. J., Unnikrishnan, M. K., Miraj, S. S., Bagchi, D., Banerjee, M., Reddy, B. S., Rodrigues, G. S., Manu, M. K., Saravu, K., Mukhopadhyay, C., \& Rao, M. (2021). Probiotics in Prevention and Treatment of COVID-19: Current Perspective and Future Prospects: Arch Med Res 2021, 52(6), 582-594. DOI: 10.1016/j.arcmed.2021.03.002.

Lange, K.W. (2021). Food science and COVID-19: Food Science and Human Wellness, 10(1), 1-5. DOI: 10.1016/j.fshw.2020.08.005. 
Latini, A., Agolini, E., Novelli, A., Borgiani, P., Giannini, R., Gravina, P., Smarrazzo, A., Dauri, M., Andreoni, M., Rogliani, P., Bernardini, S., Helmer-Citterich, M., Biancolella, M., \& Novelli, G. (2020). COVID-19 and Genetic Variants of Protein Involved in the SARS-CoV-2 Entry into the Host Cells: Genes, 11(9), 1010. DOI: https://doi.org/10.3390/ genes11091010.

Maes, M., Del, T., Junior, W., Lozovoy, M., Mori, M.T.E., Danelli, T., Almeida, E.R.D., Tejo, A.M., Tano, Z. N., Reiche, E. M. V. (2021). In COVID-19, NLRP3 inflammasome genetic variants are associated with critical disease and these effects are partly mediated by the sickness symptom complex: a nomothetic network approach: medRxiv, 5(3),98. DOI:: 10.1101/2021.09.26.21264127.

Maggini, S., Pierre, A., Calder, P.C. (2018). Immune Function and Micronutrient Requirements Change over the Life Course: Nutrients, 10(10), 1531.DOI:10.3390/nu 10101531.

Makki, K., Froguel, P., Wolowczuk, I. (2013). Adipose tissue in obesity-related inflammation and insulin resistance: cells, cytokines, and chemokines: ISRN Inflamm, 2013,139239. DOI:10.1155/2013/139239.

McCoy, J., Wambier, C. G., Vano-Galvan, S., Shapiro, J., Sinclair, R., Ramos, P. M., Washenik, K., Andrade, M., Herrera, S., Goren, A. (2020). Racial variations in COVID-19 deaths may be due to androgen receptor genetic variants associated with prostate cancer and androgenetic alopecia. Are anti-androgens a potential treatment for COVID-19: J Cosmet Dermatol,19(7),1542-1543. DOI:10.1111/ jocd. 13455 .

Mertens, E., Penalvo, J.L. (2021). The Burden of Malnutrition and Fatal COVID-19: A Global Burden of Disease Analysis: Frontiers in Nutrition,7, 351. DOI: 10.3389/fnut.2020. 619850 .
Nikola, K. Anita, S. Kristel, K. (2021). Association of Vitamin D, Zinc and Selenium Related Genetic Variants With COVID-19 Disease Severity: Frontiers in Nutrition,8,289. DOI: 10.3389/fnut.2021.689419.

Octavia, L., Harlan, J. (2021). The role of nutrition the COVID-19 pandemic: International Journal of Public Health Science, 10 (2), 304-310. DOI: 10.11591/ijphs. v10i2.20662.

Pairo, C. E., Clohisey, S., Klaric, L., Breherick, A.D., Rawlik, K., Pasko, D.,Walker, S., Parkinson, N., Fourman, M.H., Russell, D.C., Furniss, J., Richmond, A., Gountouna, E., Wrobel, N., Harrison, D., Wang, Bo., Wu, Y., Meynert, A. (2021). Genetic mechanisms of critical illness in COVID-19: Nature, 591(7848), 92-98. DOI: https://doi.org/ 10.1038/s41586-020-03065-y.

Pairo, C. E., Clohisey, S., Klaric, L., Breherick, A.D., Rawlik, K., Pasko, D.,Walker, S., Parkinson, N., Fourman, M.H., Russell, D.C., Furniss, J., Richmond, A., Gountouna, E., Wrobel, N., Harrison, D., Wang, Bo., Wu, Y., Meynert, A. (2021). Genetic mechanisms of critical illness in COVID-19: Nature, 591(7848), 92-98. DOI:10.1038/s41586020-03065-y

Paraiso, I.L., Revel, J.S., Stevens, J.F. (2020). Potential use of polyphenols in the battle against COVID-19: Curr Opin Food Sci, 32, 149-155. DOI: 10.1016/j.cofs.2020.08.004.

Rescenko, R., Peculis, R., Briviba, M., Ansone, L., Terentjeva, A., Litvina, H. D., Birzniece, L., Megnis, K., Kolesova, O., Rozentale, B., Viksna, L., Rovite, V., Klovins, J. (2021). Replication of LZTFL1 gene region as a susceptibility locus for COVID-19 in Latvian population: medRxiv., 4(5),65. 
Salazar, R. E., Kalantar, Z. K., Badillo, H., Calderon, J. M., Garcia, B. C. A., Ledesma-Perez, P. D., Lerma, A., Lerma, C. (2021). Association between severity of COVID-19 symptoms and habitual food intake in adult outpatients: BMJ Nutrition, Prevention \& Health, e000348. DOI: https://doi.org/ 10.1136/bmjnph-2021-000348.

Santos, A., Magro, D.O., Evangelista, P. R., Saad, M.J.A. (2021). Diabetes, obesity, and insulin resistance in COVID-19: molecular interrelationship and therapeutic implications: Diabetol Metab Syndr , 13, 23. DOI: https://doi.org/10.1186/s13098-021-00639-2

Saponi, C. J.M.R., Rivas, M.D., Calle, F., Muñoz-Torrero, J.F.S., Costo, A., Martin, C. and Zamorano, J. (2021). IFNL4 genetic variant can predispose to COVID-19: medRxiv, 8(3),245.

Ellinghaus, D., Degenhardt, F., Bujanda, L., Buti, M., Albillos, A., Invernizzi, P., Fernandez, J., Prati, D., Baselli, G., Asselta, R., Grimsrud, M. M., Milani, C., Aziz, F., Kässens, J., May, S., Wendorff, M., Wienbrandt, L., Uellendahl-Werth, F., Zheng, T., Karlsen, T. H. (2020). Genome-wide Association Study of Severe Covid-19 with Respiratory Failure: The New England journal of medicine, 383(16), 1522-1534. DOI: https://doi.org/10.1056 /NEJMoa2020283.

Shakoor, H., Feehan, J., Mikkelsen, K., Al Dhaheri, A. S., Ali, H. I., Platat, C., Ismail, L. C., Stojanovska, L., Apostolopoulos, V. (2021). Be well: A potential role for vitamin $B$ in COVID-19: Maturitas. 144, 108-111. DOI: 10.1016/j.maturitas.2020.08.007.

Simopoulos, A. P., Serhan, C. N., \& Bazinet, R. P. (2021). The need for precision nutrition, genetic variation and resolution in Covid-19 patients: Molecular Aspects of Medicine, 77,1-6. DOI: https://doi.org/10.1016/ j.mam.2021.100943.
Singh, H., Choudhari, R., Nema, V., \& Khan, A. A. (2021). ACE2 and TMPRSS2 polymorphisms in various diseases with special reference to its impact on COVID-19 disease: Microbial pathogenesis, 150(104621). DOI: https://doi.org/10.1016/j.micpath.2020.104621

Skrajnowska, D., Brumer, M., Kankowska, S., Matysek, M., Miazio, N., Bobrowska-Korczak, B. (2021). Covid 19: Diet Composition and Health: Nutrients, 13 (9), 2980. DOI: https://doi.org/10.3390/nu13092980.

Strope, J.D., Pharm, D. C., Figg, W.D. (2020). TMPRSS2: Potential Biomarker for COVID-19 Outcomes: Journal of clinical pharmacology, 60(7), 801-807. DOI: https://doi.org/10.1002/jcph.1641.

Tsalamandris, S., Antonopoulos, A. S., Oikonomou, E., Papamikroulis, G. A., Vogiatzi, G., Papaioannou, S., Deftereos, S., \& Tousoulis, D. (2019). The Role of Inflammation in Diabetes: Current Concepts and Future Perspectives: Eur Cardiol,14(1),50-59. DOI:10.15420/ecr.2018. 33.1.

Vander, M. C. I., Simons, A., Schuurs, H. J., Vanden, H. G., Mantere, T., Kersten, S., Van, D. R. C., Steehouwer, M., Van, R. S. V., Jaeger, M., Hofste, T., Astuti, G., Corominas, G. J., Klijn, E., Fiddelaers, J., Hoischen, A. (2020). Presence of Genetic Variants Among Young Men with Severe COVID-19: JAMA, 324(7), 663-673. DOI: https://doi.org/10.1001/jama. 2020.13719 .

Velavan, T. P., Pallerla, S. R., Rüter, J., Augustin, Y., Kremsner, P. G., Krishna, S., \& Meyer, C. G. (2021). Host genetic factors determining COVID-19 susceptibility andseverity: EBioMedicine, 72(103629). DOI: https://doi.org/10.1016/j.ebiom.2021.103629. 
Vietzen, H., Rückert, T., Hartenberger, S., Honsig, C., Jaksch, P., Geleff, S., Hammer, Q., Romagnani, C., Segura, W. M., \& Puchhammer, S. E. (2021). Extent of Cytomegalovirus Replication in the Human Host Depends on Variations of the HLA-E/UL40 Axis: mBio, 12(2), e02996-20. DOI: https://doi.org/10.1128/mBio.02996-20.

Wambier, C. G., Goren, A., Vano, G. S., Ramos, P. M., Ossimetha, A., Nau, G., Herrera, S., \& McCoy, J. (2020) Androgen sensitivity gateway to COVID-19 disease severity: Drug development research, 81(7), 771-776. DOI: https://doi.org/10.1002/ddr.21688.

Wang, F., Huang, S., Gao, R., Zhou, Y., Lai, C., Li, Z., Xian, W., Qian, X., Li, Z., Huang, Y., Tang, Q., Liu, P., Chen, R., Liu, R., Li, X., Tong, X., Zhou, X., Bai, Y., Duan, G., Zhang, T., Liu, L. (2020). Initial whole-genome sequencing and analysis of the host genetic contribution to COVID-19 severity and susceptibility. Cell Discov, 6(1), 83. DOI:10.1038/s41421020-00231-4.

Whittemore, P.B. (2020). COVID-19 fatalities, latitude, sunlight, and vitamin D: Am J Infect Control, 48(9),1042-1044. DOI: 10.1016/j.ajic.2020.06.193.

Wu, L., Zhu, J., Liu, D. (2021). An integrative multiomics analysis identifies putative causal genes for COVID-19 severity. Genetics in medicine: official journal of the American College of Medical Genetics, 23(11), 2076-2086. DOI: https://doi.org/10.1038/s 41436-021-01243-5.

Zeberg, H., Pääbo, S. (2020). The major genetic risk factor for severe COVID-19 is inherited from Neanderthals: Nature, 587(7835), 610-612. DOI: https://doi.org/10.1038/ s41586-020-2818-3.
Wu, L., Zhu, J., Liu, D. (2021). An integrative multiomics analysis identifies putative causal genes for COVID-19 severity. Genetics in medicine: official journal of the American College of Medical Genetics, 23(11), 2076-2086. DOI: https://doi.org/10. 1038/s 41436-021-01243-5.

Zeberg, H., Pääbo, S. (2020). The major genetic risk factor for severe COVID-19 is inherited from Neanderthals: Nature, 587(7835), 610-612. DOI: https://doi.org/10.1038/s 41586-020-2818-3. 